\title{
Future prospect of remote Cat-CVD on the basis of the production, transportation and detection of $\mathrm{H}$ atoms
}

\author{
Hironobu Umemoto $^{1, *}$, Hideki Matsumura ${ }^{2}$ \\ ${ }^{1}$ Faculty of Engineering, Shizuoka University, Johoku, Hamamatsu, Shizuoka 432-8561, Japan \\ ${ }^{2}$ School of Materials Science, Japan Advanced Institute of Science and Technology, Asahidai, Nomi, \\ Ishikawa 923-1292, Japan
}

\begin{abstract}
The future prospect of remote Cat-CVD, in which the decomposition and the deposition chambers are separated, is discussed on the basis of the absolute density measurements of $\mathrm{H}$ atoms. It is now well recognized that uniform deposition is possible on a large area without plasma damages by Cat-CVD. However, we may not overlook the demerits in Cat-CVD. One of the demerits is the poisoning of the catalyzer surfaces by the material gases, both temporary and permanent. One technique to overcome this problem is remote Cat-CVD. The question is how to separate the decomposition and deposition areas. If the separation is not enough, there should be back diffusion of the material gases, which will poison the catalyzers. If the separation is too tight, radicals may not effuse out from the decomposition chamber. These problems are discussed and it is shown that $\mathrm{SiO}_{2}$ coating to reduce the radical recombination rates on walls is promising. The possibility of the polytetrafluoroethene coating by Cat-CVD is also discussed.
\end{abstract}

\section{Keywords}

Catalytic chemical vapor deposition, Cat-CVD, Hot-Wire CVD, Remote CVD, Gas-phase diagnoses 
*Corresponding author: Tel +81-53-478-1275; fax +81-53-478-1275.

E-mail address: thumemo(at)ipc.shizuoka.ac.jp

\section{Introduction}

In 1910s, Langmuir found that molecular hydrogen can be decomposed into atomic hydrogen efficiently on heated $\mathrm{W}$ filaments [1-3]. The heat loss from $\mathrm{W}$ wires in the presence of $\mathrm{N}_{2}, \mathrm{Hg}, \mathrm{Ar}$ and $\mathrm{CO}$ varied with the temperature accurately, as expressed by an equation of ordinary heat conduction. The heat loss in $\mathrm{H}_{2}$ also followed the same law up to $1900 \mathrm{~K}$. However, it increased rapidly over this temperature up to $3500 \mathrm{~K}$. From the power consumption analysis, he estimated the degrees of dissociation at various temperatures. The production of atomic hydrogen was further confirmed by the reduction of $\mathrm{WO}_{3}$ and $\mathrm{PtO}_{2}$, which were not reduced by molecular hydrogen. This may be regarded as the starting point of the present Cat-CVD (Catalytic Chemical Vapor Deposition, often called Hot-Wire CVD) techniques.

It may be considered that, in catalytic decomposition, the $[\mathrm{H}] /\left[\mathrm{H}_{2}\right]$ population ratio in the gas phase is not large judging from the small Boltzmann factor; $\exp (-\Delta H / R T)=4.2 \times 10^{-11}$ at $2200 \mathrm{~K}$ and $2.6 \times 10^{-8}$ at $3000 \mathrm{~K}$. Here, $\Delta H$ is the standard enthalpy change for the dissociation of $\mathrm{H}_{2}$ and $T$ is the gas-phase temperature, which may not exceed the catalyzer temperature. However, this is not the case because the entropy term, $\exp (\Delta S / R)$, in the equilibrium constant compensates the small Boltzmann factor. Under the assumption of rigid rotation and harmonic oscillation for $\mathrm{H}_{2}, \exp (\Delta S / R)$ is calculated to be $1.7 \times 10^{5}$ at $2200 \mathrm{~K}$. Besides this, Le Chatelier's principle for equilibrated $\mathrm{H}_{2}$ and $2 \mathrm{H}$ reminds us that the relative H-atom population must be larger at lower pressures usually employed in Cat-CVD 
processes. The calculated $[\mathrm{H}] /\left[\mathrm{H}_{2}\right]$ population ratio under thermal equilibrium at $2200 \mathrm{~K}$ is 0.003 at $1.0 \times 10^{5} \mathrm{~Pa}$, while that increases up to 0.5 at $5 \mathrm{~Pa}$. In addition, some non-equilibrium effect is expected when small-diameter wires are used. Jansen et al. have shown that the H-atom density is higher when wires were used instead of sheets as catalyzers [4]. The diffusional loss of $\mathrm{H}$ atoms near a wire must be more rapid than that of $\mathrm{H}_{2}$ molecules. This effect is remarkable when the wire size is the same order as the mean free path in the gas phase.

The present authors determined the $[\mathrm{H}] /\left[\mathrm{H}_{2}\right]$ population ratio experimentally to be 0.15 when the W catalyzer temperature was $2200 \mathrm{~K}$ in the presence of $5.6 \mathrm{~Pa}$ of $\mathrm{H}_{2}[5,6]$. The distance between the catalyzer and the detection zone was $10 \mathrm{~cm}$. Meier et al. have also reported the $[\mathrm{H}] /\left[\mathrm{H}_{2}\right]$ ratio to be 0.1 , when the Ta catalyzer temperature was $2540 \mathrm{~K}$ in the presence of $1.0 \mathrm{kPa}$ of $\mathrm{H}_{2}[7,8]$. The distance between the catalyzer and the detection zone was $28 \mathrm{~mm}$. Similar measurements were carried out by Connell et al. who have reported the ratio to be 0.02 when the $\mathrm{W}$ catalyzer temperature was $2373 \mathrm{~K}$ in the presence of $3.1 \mathrm{kPa}$ of $\mathrm{H}_{2}$ [9]. These population ratios are much larger that those in weakly ionized plasma. It should also be pointed out that the vibrational temperature of $\mathrm{H}_{2}$ is much lower than that of the catalyzer [10]. This suggests that the $\mathrm{H}-\mathrm{H}$ bond dissociation is much more efficient than the vibrational excitation on the catalyzer surfaces.

\section{Ideas of remote Cat-CVD}

Every technique has weak points. That in Cat-CVD should be the poisoning of the catalyzer surfaces by the material gases. For example, in a pure $\mathrm{NH}_{3}$ system, it is easy to decompose $\mathrm{NH}_{3}$ more than $50 \%$. However, when a tiny amount of $\mathrm{SiH}_{4}$ is introduced, the decomposition efficiency decreases drastically, down to $5 \%$, although that partially recovers by the addition of $\mathrm{H}_{2}[11,12]$. This problem, in principle, can be avoided by separating the decomposition chamber and the deposition 
chamber. This procedure should be called remote Cat-CVD. This should be useful not only in the above $\mathrm{NH}_{3} / \mathrm{SiH}_{4}$ systems but also in $\mathrm{H}_{2} / \mathrm{SiH}_{4}$ systems. If $\mathrm{H}$ atoms produced by catalytic decomposition from $\mathrm{H}_{2}$ can be transported without loss, it is possible to produce $\mathrm{SiH}_{3}$ radicals selectively in the reaction between $\mathrm{H}$ and $\mathrm{SiH}_{4}$ without co-producing other active species such as $\mathrm{SiH}_{2}$ and $\mathrm{Si}_{2} \mathrm{H}_{4}$.

The idea of remote CVD processes is not new. Remote plasma-enhanced CVD (PECVD) is one of the useful techniques to deposit films without plasma damages and has been studied extensively since 1980s [13-18]. Among them, expanding thermal plasma CVD is noticeable [19-22]. In thermal plasma, the gas temperature can be over $10^{4} \mathrm{~K}$ and it is not surprising if atmospheric pressure of $\mathrm{H}_{2}$ is decomposed almost completely. Radical species, such as $\mathrm{H}$ atoms, are produced in a small region kept at high pressure (such as $40 \mathrm{kPa}$ ) and are expanded to a large low-pressure (such as $20 \mathrm{~Pa}$ ) deposition chamber through a nozzle. Plasma damages must be minimized in this technique, but it may be difficult to deposit on a large area, such as $1 \mathrm{~m} \times 1 \mathrm{~m}$, uniformly by this technique.

There are few studies on remote Cat-CVD. Remote techniques are currently necessary for the further development of Cat-CVD techniques. Of course, the merit of Cat-CVD that uniform deposition on a large area without damages must not be lost. As has been discussed, the decomposition efficiency decreases with the increase in the material gas pressure. In other words, it is difficult to produce extremely high-density $\mathrm{H}$ atoms in a small volume in catalytic decomposition as for expanding thermal plasma. On the other hand, in Cat-CVD, it is easy to increase the total number of $\mathrm{H}$ atoms by using a long wire and a large-volume chamber. It should be stressed here that, in order to attain a large deposition rate, the removal rates of radical species on the decomposition chamber must be small. The main removal process in the decomposition chamber should be the heterogeneous one on walls. The homogeneous three-body recombination process of $\mathrm{H}$ atoms in the gas phase is rather slow, the rate constant of which is $8.8 \times 10^{-33} \mathrm{~cm}^{-6} \mathrm{~s}^{-1}$ at room temperature when the third body is $\mathrm{H}_{2}$ [23]. Of 
course, the rate constant decreases with the increase in the gas temperature.

In remote PECVD, since the plasma region is, in general, small, it is possible to use glass materials, which are rather inert in the recombination of radical species [24-31]. In Cat-CVD, however, the volume of the radical production region must be large and it is desired to use a firm metal chamber. In addition, a large partition wall with many pin holes is necessary to separate the decomposition chamber and the deposition chamber. Without a partition wall, the pressure gradient will be too small to prevent the back-diffusion of the material gases. It is important to lower the radical recombination probability on the partition walls, too.

\section{Coating techniques of the chamber walls and the $\mathrm{H}$-atom density measurements}

It is well established that $\mathrm{H}$-atom loss probabilities on glasses including fused quartz are smaller than those on metal surfaces at least by one order of magnitude [24-31]. Then, we have tried to coat the chamber walls with $\mathrm{SiO}_{2}$ and found that this coating is useful to reduce the surface loss of $\mathrm{H}$ atoms [32]. A xylene solution of perhydropolysilazane was smeared on chamber walls, which can easily be oxidized in air at low temperatures such as below $400 \mathrm{~K}[33,34]$. This procedure produces a chemically stable, dense, nonporous, adhesive and flat $\mathrm{SiO}_{2}$ coating. We have shown that the steady-state density of $\mathrm{H}$ atoms can be increased by one order of magnitude by this $\mathrm{SiO}_{2}$ coating in single-chamber experiments [32].

The absolute densities of $\mathrm{H}$ atoms were measured by a vacuum-ultraviolet (vuv) laser absorption technique at $121.6 \mathrm{~nm}$ in the above study. Many spectroscopic techniques can detect $\mathrm{H}$ atoms in the gas phase, including vuv absorption spectroscopy, vuv laser induced fluorescence, two-photon laser induced fluorescence, resonance-enhanced multiphoton ionization and electron spin resonance [5,35-42]. Among them, only absorption technique can determine the absolute densities without calibrations. 
Both lasers and conventional light sources can be used, but special care must be paid when a conventional light source is used to avoid the reversal of the emission profiles of the resonance radiation $[37,43,44]$. No such attention is necessary when lasers are used. Besides this, in lasers, since it is possible to scan the wavelength, it is easy to separate the absorption by $\mathrm{H}$ atoms and by other vuv absorbing gases such as $\mathrm{NH}_{3}$ and $\mathrm{SiH}_{4}$ [45-47].

Recently, we have succeeded in the transportation of $\mathrm{H}$ atoms by using a two-chamber system; the decomposition chamber was $18 \mathrm{~cm}$ in internal diameter and $45 \mathrm{~cm}$ in length, and the deposition chamber was $45 \mathrm{~cm}$ in internal diameter [48]. This shows that coating techniques are useful to realize remote Cat-CVD. When the inside of both chambers was coated with $\mathrm{SiO}_{2}$, it was easy to increase the $\mathrm{H}$-atom density in the deposition chamber more than $10^{11} \mathrm{~cm}^{-3}$. The pressure in the deposition chamber was kept at 5.6 Pa, while that in the decomposition chamber was ten times higher. The catalyzer length was $30 \mathrm{~cm}$. The catalyzer temperature dependences of the $\mathrm{H}$-atom density are listed in table 1. It may be easy to increase the $\mathrm{H}$-atom density to $10^{12} \mathrm{~cm}^{-3}$ by optimizing the flow conditions as well as the catalyzer temperature and the length. The details will be published elsewhere [48]. Besides $\mathrm{SiO}_{2}$, polytetrafluoroethene is also known to have a low recombination rate of $\mathrm{H}$ atoms [49]. Polytetrafluoroethene coating by Cat-CVD has been reported by Gleason and her coworkers [50,51]. The investigation of the effect of this coating is also in progress in our laboratory.

\section{Conclusions}

It is important to develop a technique to transport $\mathrm{H}$ atoms without losses. This is because, by this technique, remote Cat-CVD, in which the decomposition and deposition areas are separated, can be established. In remote Cat-CVD, it will be possible to avoid the poisoning of the catalyzer surface by the material gases. In order to put this technique into practice, it is necessary to lower the removal rates 
of radical species on chamber walls. $\mathrm{SiO}_{2}$ coating of the chamber walls as well as the separation walls is useful to decrease the recombination rates of $\mathrm{H}$ atoms. Oxidation of perhydropolysilazane can be used for this purpose. Polytetrafluoroethene coating by Cat-CVD is also in expectation. 


\section{References}

[1] I. Langmuir, J. Am. Chem. Soc. 34 (1912) 860.

[2] I. Langmuir, GM.J. Mackay, J. Am. Chem. Soc. 36 (1914) 1708.

[3] I. Langmuir, J. Am. Chem. Soc. 37 (1915) 417.

[4] F. Jansen, I. Chen, M.A. Machonkin, J. Appl. Phys. 66 (1989) 5749.

[5] H. Umemoto, K. Ohara, D. Morita, Y. Nozaki, A. Masuda, H. Matsumura, J. Appl. Phys. 91 (2002) 1650.

[6] H. Umemoto, Y. Nozaki, M. Kitazoe, K. Horii, K. Ohara, D. Morita, K. Uchida, Y. Ishibashi, M. Komoda, K. Kamesaki, A. Izumi, A. Masuda, H. Matsumura: J. Non-Cryst. Solids 299-302 (2002) 9.

[7] U. Meier, K. Kohse-Hoinghaus, L. Schafer, C.-P. Klages, Appl. Opt. 29 (1990) 4993.

[8] L. Schäfer, C.-P. Klages, U. Meier, K. Kohse-Höinghaus, Appl. Phys. Lett. 58 (1991) 571.

[9] L.L. Connell, J.W. Fleming, H.-N. Chu, D.J. Vestyck, Jr., E. Jensen, J. E. Butler, J. Appl. Phys. 78 (1995) 3622.

[10] H. Umemoto, S.G. Ansari, H. Matsumura, J. Appl. Phys. 99 (2006) 043510.

[11] H. Umemoto, T. Morimoto, M. Yamawaki, Y. Masuda, A. Masuda, H. Matsumura, Thin Solid Films 430 (2003) 24.

[12] S.G. Ansari, H. Umemoto, T. Morimoto, K. Yoneyama, A. Izumi, A. Masuda, H. Matsumura, Thin Solid Films 501 (2006) 31.

[13] L.G. Meiners, J. Vac. Sci. Tech. 21 (1982) 655.

[14] P.D. Richard, R.J. Markunas, G. Lucovsky, GG. Fountain, A.N. Mansour, D.V. Tsu, J. Vac. Sci. Tech. A3 (1985) 867.

[15] G. Lucovsky, P.D. Richard, D.V. Tsu, S.Y. Lin, R.J. Markunas, J. Vac. Sci. Tech. A 4 (1986) 681. [16] A.M. Wrobel, S.Wickramanayaka, Y. Hatanaka, J. Appl. Phys. 76 (1994) 558. 
[17] Y.-B. Park, J.-K. Kang, S.-W. Rhee, Thin Solid Films 280 (1996) 43.

[18] T. Lauinger, J. Moschner, A.G. Aberle, R. Hezel, J. Vac. Sci. Tech. A 16 (1998) 530.

[19] M.C.M. van de Sanden, R.J. Severens, W.M.M. Kessels, R.F.G. Meulenbroeks, D.C. Schram, J. App. Phys. 84 (1998) 2426; 85 (1999) 1243.

[20] W.M.M. Kessels, C.M. Leewis, M.C.M. van de Sanden, D.C. Schram, J. App. Phys. 86 (1999) 4029.

[21] W.M.M. Kessels, R.J. Severens, A.H.M. Smets, B.A. Korevaar, GJ. Adriaenssens, D.C. Schram, M.C.M. van de Sanden, J. App. Phys. 89 (2001) 2404.

[22] W.M.M. Kessels, A. Leroux, M.GH. Boogaarts, J.P.M. Hoefnagels, M.C.M. van de Sanden, D.C. Schram, J. Vac. Sci. Tech. A 19 (2001) 467.

[23] D.L. Baulch, C.J. Cobos, R.A. Cox, C. Esser, P. Frank, Th. Just, J.A. Kerr, M.J. Pilling, J. Troe, R.W. Walker, J. Warnatz, J. Phys. Chem. Ref. Data 21 (1992) 411.

[24] A. Rousseau, A. Granier, G. Gousset, P. Laprince, J. Phys. D 27 (1994) 1412.

[25] L. Tomasini, A. Rousseau, G. Baravian, G. Gousset, P. Laprince, Appl. Phys. Lett. 69 (1996) 1553.

[26] A. Rousseau, G. Cartry, X. Duten, J. App. Phys. 89 (2001) 2074.

[27] P. Kae-Nune, J. Perrin, J. Jolly, J. Guillon, Surf. Sci. 360 (1996) L495.

[28] B.J. Wood, H. Wise, J. Phys. Chem. 66 (1962) 1049.

[29] Y.C. Kim, M. Boudart, Langmuir 7 (1991) 2999.

[30] A.D. Tserepi, T.A. Miller, J. Appl. Phys. 75 (1994) 7231.

[31] J. Perrin, M. Shiratani, P. Kae-Nune, H. Videlot, J. Jolly, J. Guillon, J. Vac. Sci. Tech. A 16 (1998) 278.

[32] S.G. Ansari, H. Umemoto, T. Morimoto, K. Yoneyama, A. Masuda, H. Matsumura, M. Ikemoto, K. Ishibashi, J. Vac. Sci. Technol. A 23 (2005) 1728.

[33] K. Kamiya, T. Tange, T. Hashimoto, H. Nasu, Y. Shimizu, Res. Rep. Faculty Eng. Mie Univ. 26 
(2001) 23 .

[34] T. Kubo, E. Tadaoka, H. Kozuka, J. Mater. Res. 19 (2004) 635.

[35] H. Umemoto, T. Nakae, H. Hashimoto, K. Kongo, M. Kawasaki, J. Chem. Phys. 109 (1998) 5844.

[36] S. Takashima, M. Hori, T. Goto, K. Yoneda, J. Appl. Phys. 89 (2001) 4727.

[37] S. Takashima, M. Hori, T. Goto, A. Kono, M. Ito, K. Yoneda, Appl. Phys. Lett. 75 (1999) 3929.

[38] H.L. Duan, GA. Zaharias, S.F. Bent, Current Opinion Solid State \& Mat. Sci. 6 (2002) 471.

[39] K. Tonokura, K. Inoue, M. Koshi, J. Non-Cryst. Solids 299-302 (2002) 25.

[40] A. Tkáč: Polym. Degrad. \& Stability 33 (1991) 171.

[41] H. Umemoto, J. Chem. Phys. 125 (2006) 034306.

[42] K. Sato, Y. Shihira, S. Tsunashima, H. Umemoto, T. Takayanagi, K. Furukawa, S. Ohno, J. Chem. Phys. 99 (1993) 1703.

[43] S. Takashima, S. Arai, M. Hori, T. Goto, A. Kono, M. Ito, K. Yoneda, J. Vac Sci. Technol. A19 (2001) 599 .

[44] H. Nagai, M. Hiramatsu, M. Hori, T. Goto, Rev. Sci. Instrum. 74 (2003) 3453.

[45] M. Suto, L.C. Lee, J. Chem. Phys. 84 (1986) 1160.

[46] U. Itoh, Y. Toyoshima, H. Onuki, N. Washida, T. Ibuki, J. Chem. Phys. 85 (1986) 4867.

[47] K. Watanabe, J. Chem. Phys. 22 (1954) 1564.

[48] H. Umemoto, S. Setoguchi, H. Uemura, H. Matsumura, to be submitted.

[49] A. Donnelly, M.P. Hughes, J. Geddes, H.B. Gilbody, Meas. Sci. Technol. 3 (1992) 528.

[50] K.K.S. Lau, H.G. Pryce Lewis, S.J. Limb, M.C. Kwan, K.K. Gleason, Thin Solid Films 395 (2001) 288.

[51] H.G. Pryce Lewis, J.A. Caulfield, K.K. Gleason, Langmuir 17 (2001) 7652. 
Table 1. H-atom densities with and without $\mathrm{SiO}_{2}$ coatings in remote Cat-CVD apparatus. The $\mathrm{H}_{2}$ pressures in the decomposition and deposition chambers were $55 \mathrm{~Pa}$ and $5.6 \mathrm{~Pa}$, respectively.

\begin{tabular}{ccc}
\hline Catalyzer temperature $/ \mathrm{K}$ & \multicolumn{2}{c}{$\mathrm{H}$-atom density $/ \mathrm{cm}^{-3}$} \\
\cline { 2 - 3 } & With $\mathrm{SiO}_{2}$ coating & Without $\mathrm{SiO}_{2}$ coating \\
\hline 1900 & $2.8 \times 10^{10}$ & \\
2100 & $5.5 \times 10^{10}$ & \\
2250 & & $2.7 \times 10^{10}$ \\
2300 & $1.0 \times 10^{11}$ & \\
2400 & & $4.1 \times 10^{10}$ \\
2500 & & $6.6 \times 10^{10}$ \\
\hline
\end{tabular}

